\title{
Resveratrol inhibits rat pulmonary fibroblast proliferation through modulation of TLR4/NF-KB pathway
}

\author{
Li Zhen-yu" ${ }^{1 \#}$, Yi Jun ${ }^{1 \#}$, Wang Qian², Yang Tian-lun', Pu Xiao-qun' and Li Chuan-chang ${ }^{1 *}$ \\ 1Department of Cardiology, Xiangya Hospital, Central South University, Changsha 410008, China. \\ 2Hunan University of Chinese Medicine, Changsha 410007, China.
}

Accepted 12 March, 2013

\begin{abstract}
Resveratrol shows a powerful therapeutic effect in several cardiovascular diseases and cancer. Recent studies suggest a protective role of resveratrol in pulmonary fibrosis, but the underlying mechanism remains unknown. The aim of the present study is to investigate the anti-inflammatory effect of resveratrol on pulmonary fibrosis and reveal the role of toll like receptor 4 (TLR4) signaling pathway during the process. Pulmonary fibrosis (PF) model in rats was induced by endotracheal perfusion of bleomycin (BLM). Resveratrol treatment was given for three weeks. Blood samples and lung tissues were collected for further investigation. Results showed that the level of interleukin(IL)-1 and IL-6 in blood and lung tissue were both elevated in PF rats when compared with control rats $(P<0.05)$. Resveratrol treatment significantly decreased IL-1 and IL-6 level $(P<0.05)$. Real-time polymerase chain reaction (PCR) and western blot both showed that TLR4 expression in lung tissue from PF rats was upregulated while resveratrol treatment significantly decreased TLR4 expression $(P<0.05)$. Furthermore, primary rat pulmonary fibroblast was cultured. Lipopolysaccharide (LPS) induced cellular proliferation and increased TLR4 and NF-KB expression while NF-KB inhibitor BAY 11-7085 abolished the cell proliferation induced by LPS. Increased TLR4 and NF-KB expression induced by LPS incubation were both diminished by resveratrol $(P<0.05)$. Cellular proliferation was also inhibited by resveratrol treatment. In conclusion, the anti-inflammatory effect of resveratrol may contribute its role in antiproliferation of pulmonary fibroblast and PF therapy. TLR4/NF-KB signaling pathway is also involved in the process.
\end{abstract}

Key words: Pulmonary fibrosis, resveratrol, TLR4, NF-KB, inflammation.

\section{INTRODUCTION}

Pulmonary fibrosis (PF) is a severe clinical disease which could induce dyspnea, pulmonary hypertension and respiratory failure. Structural damage is the major characteristic of PF and usually happens prior to functional changes. Fibrotic tissues replace the normal lung parenchyma gradually (Noble et al., 2012), while proliferation of pulmonary fibroblast plays an important role during the process (Taniguchi et al., 2010).
The pathophysiology mechanism of PF has not been fully revealed so far. Most cases of PF may present as secondary outcome of other lung diseases, such as autoimmune disorders, viral infections or other microscopic injuries to the lung. Some cases can also be developed without any known cause, which was called idiopathic pulmonary fibrosis. It has been well recognized that inflammation was a common feature in various PF even in

*Corresponding author. E-mail: huaqiangzhai@126.com. Tel: +86-10-84738630.

\#These authors made equal contribution to the work. 
idiopathic cases (Bringardner et al., 2008), and toll like receptor 4 (TLR4) play a critical role in inflammatory response. Recently, several researches suggested that TLR4 signaling pathway is involved in PFprocess. It was reported that TLR4 activity was required in the resolution of pulmonary inflammation and fibrosis after acute and chronic lung injury (Yang et al., 2012). Treatment targeted on TLR4 signaling pathway was thought as an effective therapeutic strategy in PF treatment (John et al., 2010).

Resveratrol was widely used for protecting cardiovascular disease and cancer. Previous study has demonstrated that resveratrol, as a antioxidant, does not only decrease reactive oxygen species (ROS) but also show an anti-inflammatory effect (Bradamante et al., 2004). Recent research suggested that resveratrol treat-ment led to inhibit PF in bleomycin (BLM)-induced PF, while the underlying mechanism remains unknown (Akgedik et al., 2012). So the present study is designed to investigate whether the anti-inflammatory effect of resveratrol is involved in its therapeutic effect of PF. We also aim to explore the role of TLR4 signaling pathway during the process.

\section{MATERIALS AND METHODS}

\section{Animals}

Male Sprague-Dawley (SD) rats weighing 150 to $180 \mathrm{~g}$ were obtained from Animal Center, Central South University (Changsha, China). All animal experiments were conducted in accordance with the National Institutes of Health Guide for the Care and Use of Laboratory Animals, the experimental protocol was approved by the Medicine Animal Welfare Committee of Xiangya School of Medicine, Central South University.

\section{Animal experiments}

Twenty four Male SD rats were divided into three groups: control group, BLM perfusion group and BLM perfusion plus resveratrol $(0.5 \mathrm{~g} / \mathrm{kg} / \mathrm{day})$ group. There were 8 rats in each group. Endotracheal perfusion of BLM (5 mg/kg) was used to build PF model in rats. Resveratrol was given by intragastric administration continuously for 3 weeks. At the end of the experiment, the animals were anesthetized by sodium pentobarbital $(30 \mathrm{mg} / \mathrm{kg}$, intraperitoneally (ip)). Blood samples were collected by strength artery intubation. Plasma were prepared and frozen in $-20^{\circ} \mathrm{C}$ for IL1 and II-6 enzyme-linked immunosorbent assay (ELISA) assay. After sacrificing the animals, the right, left lung lobes were dissected. The freshly isolated lung tissue samples were used for mRNA and protein expression analysis. Excised lungs were fixed in $4 \%$ paraformaldehyde for hematoxylin-eosin and immunohistochemistry staining.

ELISA and immunohistochemistry analysis of interleukin (IL)-1 and IL-6

Plasma concentration of IL- 1 and IL- 6 was determined by ELISA kits (R\&D Systems Inc, Hong Kong, China), and the procedure according to the manufacturer's instructions.

\section{Cell experiments}

Pulmonary fibroblasts were prepared from the pulmonary lobe of male 10-week-old SD rats using explant method as described previously (Serlin et al., 2006). The cells were cultured at $37^{\circ} \mathrm{C}$ under $5 \% \mathrm{CO}_{2}$ in Dulbecco's modified Eagle's medium containing $20 \%$ fetal bovine serum. The cells between passages 3 and 8 were used for the experiments. The cells were divided into 6 groups as follows: (1) Control: cells were treated with $21 \% \mathrm{O}_{2}$ for $48 \mathrm{~h}$; (2) +lipopolysaccharide (LPS), cells were stimulated to proliferate by exposure to LPS $(10 \mathrm{ng} / \mathrm{ml})$ for $48 \mathrm{~h}$; (3) +LPS plus low dose resveratrol $(10 \mu \mathrm{M})$ : cells were pre-treated with resveratrol for $1 \mathrm{~h}$, and then subjected to LPS for $48 \mathrm{~h}$; (4) +LPS plus medium dose resveratrol $(50 \mu \mathrm{M})$ : cells were pre-treated with resveratrol for $1 \mathrm{~h}$, and then subjected to LPS for $48 \mathrm{~h}$; (5) +LPS plus high dose resveratrol $(100 \mu \mathrm{M})$ : cells were pre-treated with resveratrol for $1 \mathrm{~h}$, and then subjected to LPS for $48 \mathrm{~h}$; $(6)+$ LPS plus BAY 11-7085 $(100 \mu \mathrm{M})$ : cells were pre-treated with resveratrol for $1 \mathrm{~h}$, and then subjected to LPS for $48 \mathrm{~h}$.

\section{Cell proliferation assays}

Cell proliferation was measured according to the DNA synthesis by BrdU marking. For the BrdU incorporation assay, cells were counted and seeded into 96-well culture plates $\left(6 \times 10^{3}\right.$ cells per well). BrdU (10 $\mu \mathrm{l} /$ well, Roche, Mannhein, Germany) was added. Cells were fixed and stained after $4 \mathrm{~h}$ according to the manufacturer's instructions. Colorimetric analysis was performed with an ELISA plate reader (DTX880; Beckman, Miami, USA) at 450 $\mathrm{nm}$.

\section{Real-time polymerase chain reaction (PCR) analysis}

Total RNA was extracted from lung tissue and pulmonary fibroblasts, respectively by using TRIzol reagent (Invitrogen, China). 0.2 to $0.5 \mu \mathrm{g}$ RNA was used for reverse transcription reaction using the PrimeScript reverse transcription reagent kit (TaKaRa, China). Quantitative analysis of the change in expression levels was performed using SYBR $®$ Premix Ex Taq ${ }^{\mathrm{TM}}$ (TaKaRa, China) by the $\mathrm{ABI} 7300$ system. PCR cycling conditions were an initial incubation at $95^{\circ} \mathrm{C}$ for $15 \mathrm{~s}$, followed by 40 cycles of denaturation at $95^{\circ} \mathrm{C}$ for 5 $\mathrm{s}$ and annealing at $60^{\circ} \mathrm{C}$ for $31 \mathrm{~s}$. Glyceraldehyde 3-phosphate dehydrogenase (GAPDH) was used to normalize the expression of mRNA. Primers for TLR4 were: forward5'CCAGAGCCGTTGGTGTATC-3', reverse5'GTGCCCTGTGAGGTCGTT-3'. Primers for IL-1 were: forward 5'CCTGTGGCCTTGGGCCTCAA-3', reverse 5'GGTGCTGATGTACCAGTTGGG-3'. Primers for IL-6 were: forward 5'- GAGAAAAGAGTTGTGCAATGGC-3', reverse 5' ACTAGGTTTGCCGAGTAGACC-3'. Primers for GAPDH were: forward 5'-TGGCCTCCAAGGAGTAAGAAAC-3', reverse 5'GGCCTCTCTCTTGCTCTCAGTATC-3'. Data analysis was performed by comparative $\mathrm{Ct}$ method using the $\mathrm{ABI}$ software.

\section{Isolation of nuclear extracts}

Nuclear protein extracts were prepared according to the manufacturer's instructions. Pulmonary fibroblasts were collected, washed twice with ice-cold phosphate-buffered saline (PBS) and lysed in $400 \mu \mathrm{l}$ total cell extract buffer A $(10 \mathrm{mmol} / \mathrm{L}$ hydroxyethy piperazineethanesulfonic (HEPES; $\mathrm{pH} 7.9$ ), $10 \mathrm{mmol} / \mathrm{L}$ potassium chloride $(\mathrm{KCl}), 0.1 \mathrm{mmol} / \mathrm{L}$ ethylenediaminetetraacetic acid (EDTA), $0.1 \mathrm{mmol} / \mathrm{L}$ ethylene glycol tetraacetic acid (EGTA), $1 \mathrm{mmol} / \mathrm{L}$ dithiothreitol (DTT), $0.5 \mathrm{mmol} / \mathrm{L}$ phenylmethylsulphonyl fluoride (PMSF)) for $15 \mathrm{~min}$ in ice. After vortexing, lysed cells were 
centrifuged at $12,000 \mathrm{~g}$ for $3 \mathrm{~min}$ at $4^{\circ} \mathrm{C}$, at which supernatant was removed by Pasteur pipette. $50 \mu \mathrm{l}$ ice-cold cell extract buffer $B(20$ $\mathrm{mmol} / \mathrm{L}$ HEPES $(\mathrm{pH} 7.9), 0.4 \mathrm{~mol} / \mathrm{L} \mathrm{NaCl}, 1 \mathrm{mmol} / \mathrm{L}$ EDTA, 1 $\mathrm{mmol} / \mathrm{L}$ EGTA, $1 \mathrm{mmol} / \mathrm{L}$ DTT, $0.5 \mathrm{mmol} / \mathrm{L}$ PMSF, 25\% (v/v) glycerine) was added into the nuclear pellets and vortexed at $4^{\circ} \mathrm{C}$ for $15 \mathrm{~min}$. The samples were centrifuged at $12,000 \mathrm{~g}$ for $5 \mathrm{~min}$ at $4^{\circ} \mathrm{C}$ and the Aliquots of the nuclear protein extracts from supernatant were collected and stored at $-70^{\circ} \mathrm{C}$. Protein content of the nuclear extracts was determined using $\mathrm{BCA}$ reagent.

\section{Electrophoretic mobility shift assay (EMSA)}

NF-KB activity was performed by EMSA. Nuclear extracts containing $15 \mu \mathrm{g}$ total protein were incubated with double-stranded NF-KB specific oligonucleotide probe end-labeled with [ $\mathrm{Y}-32 \mathrm{P}]$ ATP using T4 polynucleotide kinase. The double-stranded DNA probe sequence is 5'-AGTTGAGGGGACTTTCCCAGGC-3' and 3'TCAACTCCCCTGAAAGGGTCCG-5' (antisense). The labeled probe was purified through Sephadex G-25. DNA-protein binding reactions were incubated for $15 \mathrm{~min}$ on ice to allow complex formation. After $10 \mathrm{~min}$ of incubation at room temperature, the samples were subjected to electrophoresis on $4 \%$ non-denaturing polyacrylamide gel at $250 \mathrm{~V}$ in $0.5 \mathrm{X}$ Tris-borate-EDTA (TBE) running buffer for $2 \mathrm{~h}$. After electrophoresis, the gel was then dried and the DNA-protein complexes were detected by autoradiography. After being dried, the gel was exposed to X-ray film at $-70^{\circ} \mathrm{C}$ for 6 to $48 \mathrm{~h}$.

\section{Western blot analysis}

Protein was extracted from lung tissue and pulmonary fibroblasts with radioimmunoprecipitation assay (RIPA) buffer (containing $0.1 \%$ PMSF), and equal amounts of protein from each sample $(30 \mu \mathrm{g})$ were separated by $10 \%$ sodium dodecyl sulfate polyacrylamide gel electrophoresis (SDS/PAGE) and transferred to polyvinylidene fluoride membranes. The membranes were then incubated with primary antibodies overnight at $4^{\circ} \mathrm{C}$, and horseradish peroxidase (HRP)-coupled goat anti-mouse secondary antibody (1:2000, Santa Cruz, California, USA). The chemiluminescence signals were detected with the EasySee Western Blot Kit (Beijing TransGen Biotech, Beijing, China). The densitometric analysis was conducted with Image J 1.43 (National Institutes of Health). Primary antibody against TLR4 (ab22048 and ab13556, 1:1000 dilution) and NF-kB (Anti-NF-KB p65, acetyl K310, 1:1000 dilution) was purchased from Abcam (Hong Kong, China), and primary antibody against GAPDH (1:2000 dilution) was obtained from Santa Cruz (California, USA).

\section{Statistical methods}

The results were presented as means \pm SEM (standard errors). Statistical analysis was performed by ANOVA followed by NewmanStudent-Keuls test for multiple comparisons. A value of $P<0.05$ was considered significant.

\section{RESULTS}

\section{Inflammatory response in BLM-induced rats}

Plasma was collected from all rats, then inflammation factors concentration in plasma were determined using ELISA method. IL-1 concentration in plasma from BLM injected rats was significantly elevated while resveratrol treatment decreased IL-1 level (Figure $1 \mathrm{~A})$. Similar to IL1 , IL-6 concentration in plasma from BLM injected rats was also significantly elevated. But resveratrol treatment only slightly decreased its level without statistical differences (Figure 1B).

\section{Resveratrol inhibited proliferation of pulmonary fibroblast induced by LPS}

The direct effect of resveratrol on pulmonary fibroblast proliferation was first investigated. Cells were cultured for $48 \mathrm{~h}$ and cell proliferation was determined by BrdU marking. LPS $(10 \mathrm{ng} / \mathrm{ml})$ incubation stimulated a significant proliferation of pulmonary fibroblast while resveratrol preincubation inhibited the effect (Figure 2).

\section{Resveratrol down-regulated TLR4 expression in vivo and in vitro}

To observe the activation of TLR4 signaling, protein was extracted from lung tissues. Then TLR4 protein expression was determined using western blot. The protein expression of TLR4 in lung tissue from BLM injected rats was significantly increased while resveratrol treatment decreased TLR4 level (Figure 3).

We investigate the direct effect of LPS and resveratrol on TLR4 expression in cells. Pulmonary fibroblast was cultured with LPS with or without resveratrol for $24 \mathrm{~h}$. RNA and protein were collected and detected by realtime PCR and western blot, respectively. LPS $(10 \mathrm{ng} / \mathrm{ml})$ incubation significantly increased TLR4 mRNA expression which was inhibited by resveratrol in dosedependent way (Figure 4A). Western blot showed the similar changes of TLR4 protein expression. TLR4 expression was induced by LPS but significantly inhibited by resveratrol in dose-dependent way (Figure 4B).

\section{Role of NF-KB in pulmonary fibroblast proliferation regulation}

Furthermore, to investigate the role of NF-KB in proliferation regulation by LPS, BAY 11-7085, a NF-KB inhibitor was used. Pre-treatment of BAY 11-7085 significantly inhibited NF-KB expression induced by LPS (Figure 5A). And we found that pre-treatment of BAY 117085 cancelled the pulmonary fibroblast proliferation induced by LPS (Figure 5B), which suggest a critical role of NF-KB in pulmonary fibroblast proliferation regulation.

\section{Resveratrol inhibited LPS-induced NF-KB activation in pulmonary fibroblast}

We investigate the direct effect of LPS and resveratrol on NF-kB expression and activity in cells. Pulmonary fibroblast 
A
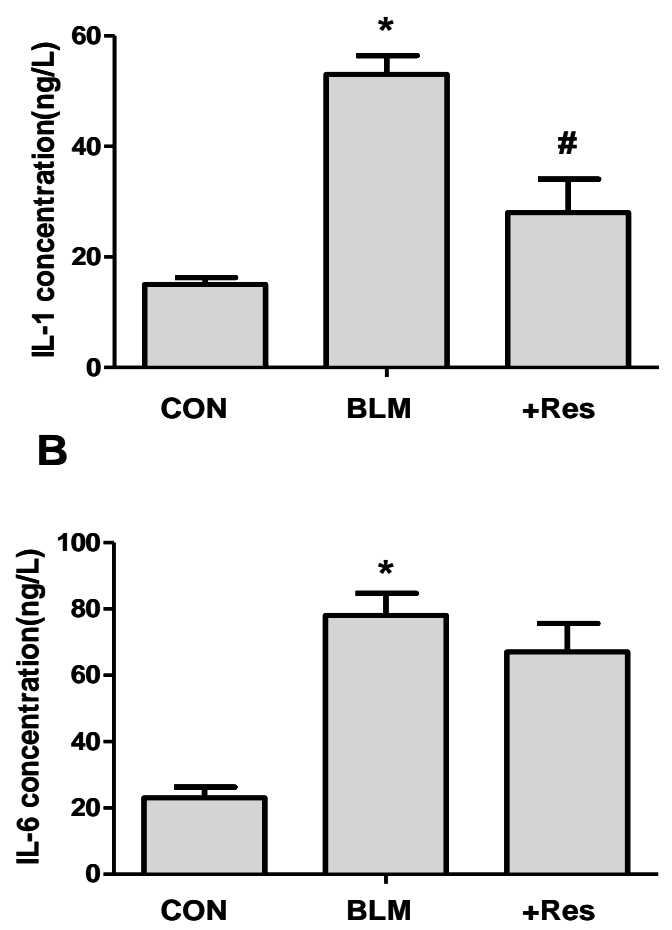

C
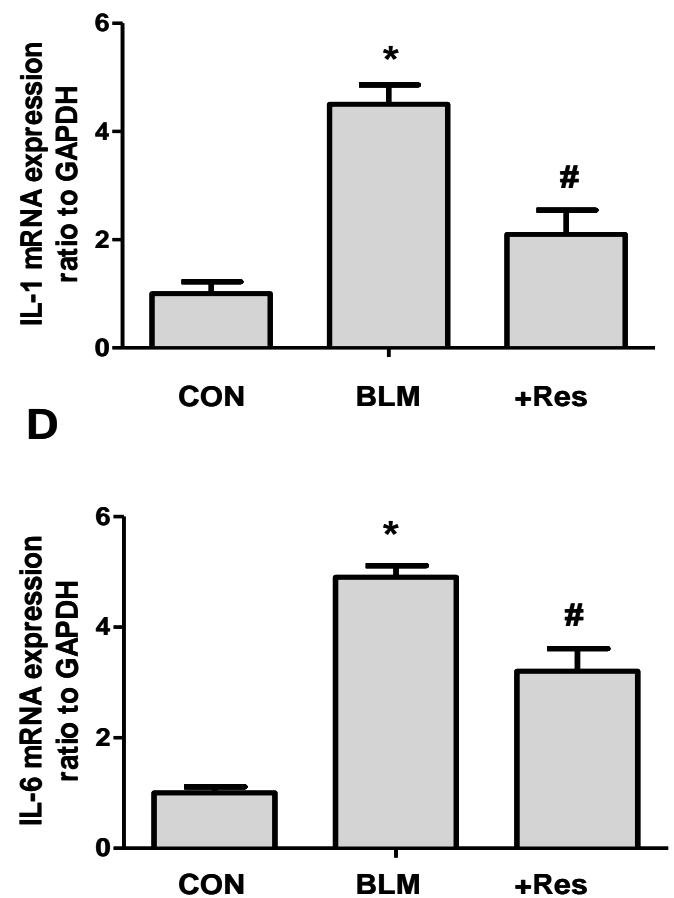

Figure 1. Plasma concentration and tissue expression of inflammatory factors. Inflammation factors concentration in plasma were determined using ELISA method. Tissue expression of inflammatory factors were determined by real-time PCR. (A) IL-1 concentration in plasma from BLM injected rats was significantly elevated $(52.7 \pm 4.3$ vs. $17.3 \pm 2.4 \mathrm{ng} / \mathrm{L})$ while resveratrol treatment decreased $\mathrm{IL}-1$ level $(24.6 \pm 5.7 \mathrm{ng} / \mathrm{L})$. (B) Similar to IL-1, IL-6 concentration in plasma from BLM injected rats was also significantly elevated (78.3 \pm 4.5 vs. $22.4 \pm 2.8 \mathrm{ng} / \mathrm{L})$. But resveratrol treatment only slightly decreased its level without statistical differences $(65.8 \pm 6.1 \mathrm{ng} / \mathrm{L})$. (C) IL-1 mRNA expression in lung tissue from BLM injected rats was significantly increased, which was down-regulated by resveratrol treatment. (D) IL-6 mRNA expression in lung tissue from BLM injected rats was significantly increased, which was down-regulated by resveratrol treatment.

${ }^{*} \mathrm{P}<0.05$ vs. control group; ${ }^{\#} \mathrm{P}<0.05$ vs. BLM group $(n=8)$ in each group. BLM: Bleomycin; Res: Resveratrol; CON: control.

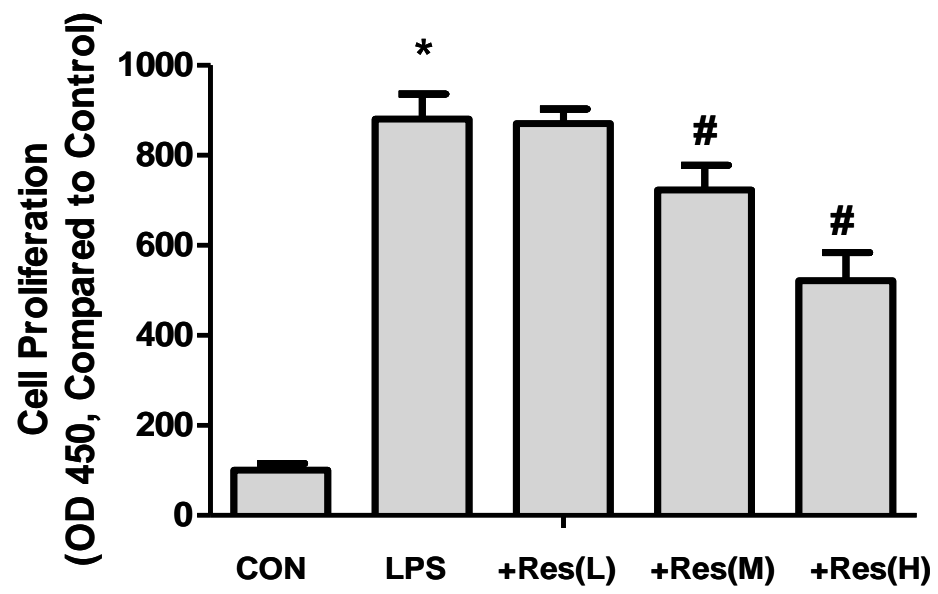

Figure 2. Effect of resveratrol on pulmonary fibroblast proliferation. Cells were cultured for $48 \mathrm{~h}$ and cell proliferation was determined by BrdU Marking. LPS (10 ng/ml) incubation stimulated a significant proliferation of pulmonary fibroblast. Resveratrol $(10,50$, and $100 \mu \mathrm{M})$ pre-incubation inhibited the proliferation does-dependently.

${ }^{*} \mathrm{P}<0.05$ vs. control group; ${ }^{\#} \mathrm{P}<0.05$ vs. LPS group $(\mathrm{n}=4)$. Res: Resveratrol; Res: Resveratrol; CON: control; LPS: lipopolysaccharide. 

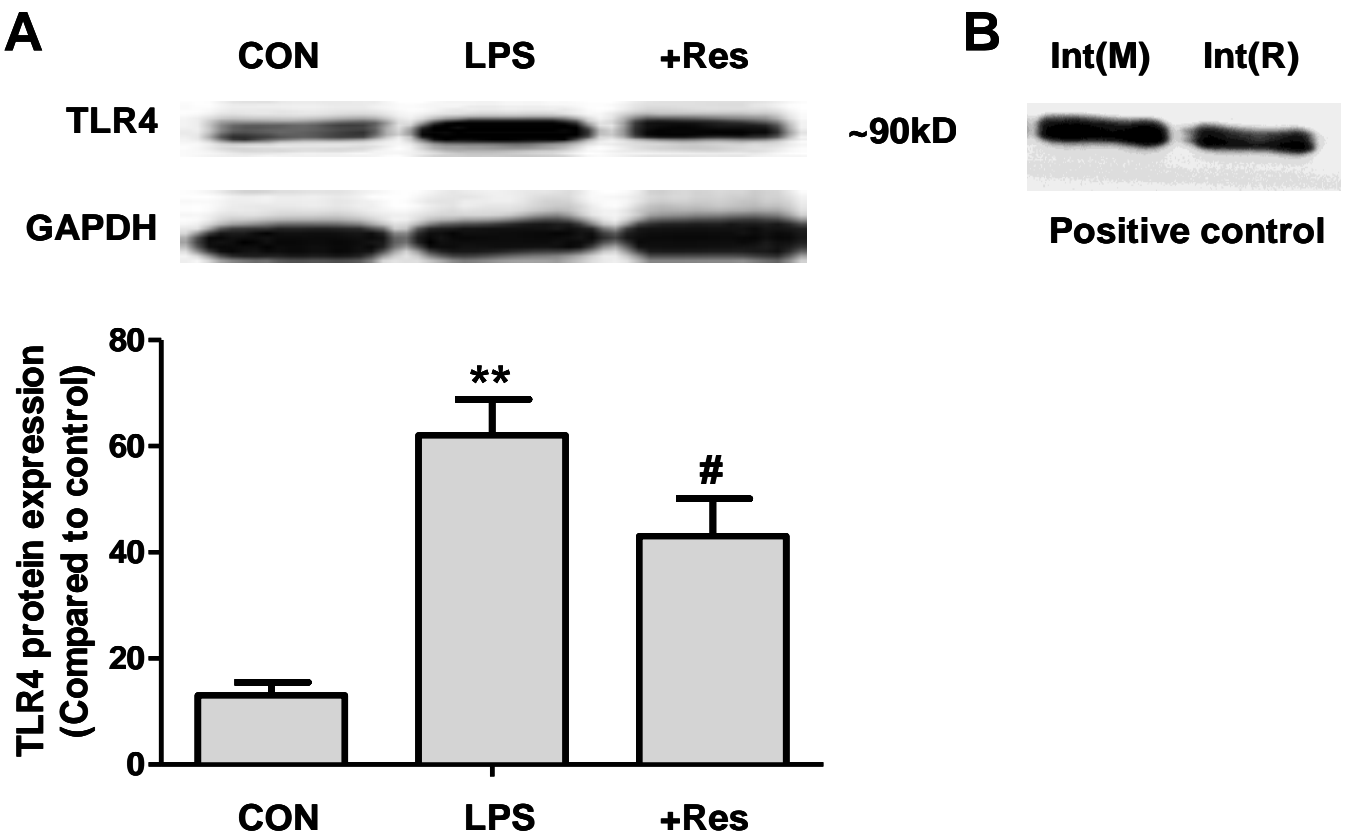

Figure 3. TLR4 expression in lung tissues. To observe the activation of TLR4 signaling, lung tissues were collected from control rats, BLM injected rats and resveratrol treatment received rats. Then TLR4 protein expression was determined using western blot. (A) The protein expression of TLR4 in lung tissue from BLM injected rats was significantly increased while resveratrol treatment decreased TLR4 level. (B) TLR4 protein expression in intestine tissue from mouse and rat, which is a positive control for TLR4 antibody.

${ }^{*} \mathrm{P}<0.05$ vs. control group; ${ }^{\#} \mathrm{P}<0.05$ vs. LPS group $(\mathrm{n}=8)$ in each group. Int: Intestine; BLM: Bleomycin; Res: Resveratrol; CON: control; LPS: lipopolysaccharide.

was cultured with LPS with or without resveratrol for $24 \mathrm{~h}$. Proteins were collected and detected by western blot. Nuclear proteins were collected for EMSA experiment. The result showed that LPS $(10 \mathrm{ng} / \mathrm{ml})$ incubation significantly up-regulated the expression and activity of NF$\mathrm{KB}$, which was inhibited by resveratrol (Figure 6).

\section{DISCUSSION}

In the present study, we examined the effect of resveratrol on LPS-induced pulmonary fibroblast proliferation, and demonstrated the critical role of TLR4 signaling pathway in the process. In vivo date showed that plasma level of inflammatory factors such as IL-1, IL6 and tumor necrosis factor (TNF)- $\alpha$ were all elevated in BLM-induced PF rats. In cultured pulmonary fibroblast, LPS incubation caused cellular proliferation and activation of TLR4-NF-kB pathway which were reversed by resveratrol. Pharmacological inhibition of NF-kB abolished the effect of LPS and resveratrol on pulmonary fibroblast proliferation.

Pulmonary fibrosis is characterized by interstitial change, it also usually be the final stage of interstitial lung disease. The pathophysiological mechanism of PF has not been fully revealed. But inflammation was thought as an important characteristic of pulmonary fibrosis and also a major reason of pulmonary fibroblast proliferation (Bringardner et al., 2008). Inflammation and the initial immune response induce secretion disorder of cytokines and chemokines. It was demonstrated that inflammatory factors such as IL-1, IL-6, monocyte chemoattractant protein-1 (MCP-1) and TNF- $\alpha$ were significantly increased in PF patients and several PF animal models (Gasse et al., 2011; Oikonomou et al., 2006). Similar situation was observed in our research as the plasma level of IL-1 and IL- 6 were all elevated in BLM-induced PF rats. The up-regulation of these inflammatory factors both in blood and lung tissue suggested that inflammation is not only a local response but also a systemic change in PF. Secretion disorder of cytokines and chemokines always caused a series of structural changes in lung. Uncontrolled proliferation of pulmonary fibroblast was one of the changes. Pulmonary fibroblast replaced the position of alveolar epithelial cells, decreased the lung compliance and hence respiratory function (Davies and Richeldi, 2002). It was also able to cause the imbalance of extracellular matrix (ECM), stimulating deposition of connective tissue, collagen, etc. Ultimately, the structural changes induce a persistent change of respiratory function (Taniguchi et al., 2010). Here, in the present study, we observed the dramatically proliferation of pulmonary fibroblast induced by LPS in vitro, while resveratrol inhibited the proliferation strongly which suggested a therapeutically 

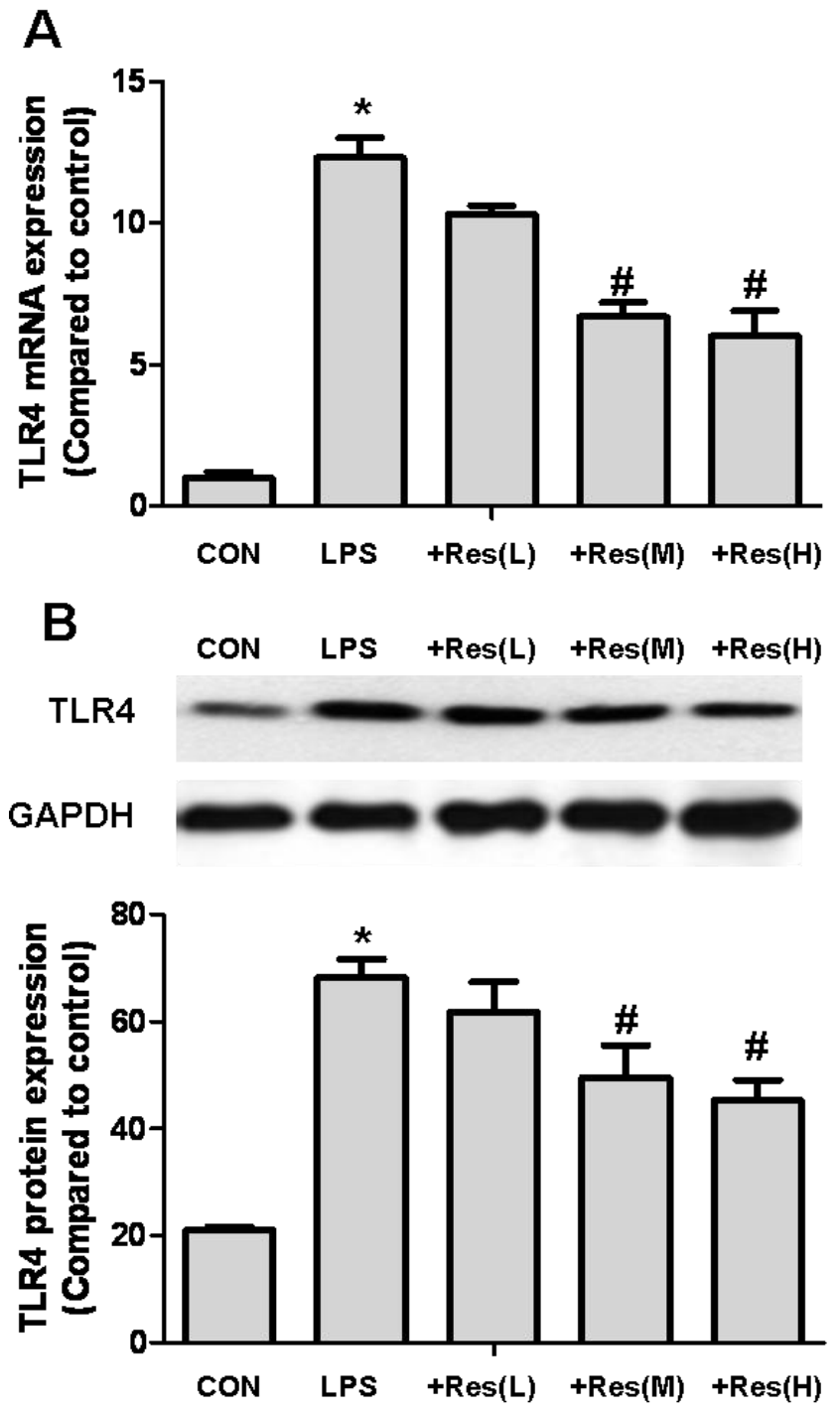

Figure 4. Effect of LPS and resveratrol on TLR4 expression in pulmonary fibroblast. We investigate the direct effect of LPS and resveratrol on TLR4 expression in cells. Pulmonary fibroblast were cultured with LPS with or without resveratrol for $24 \mathrm{~h}$. RNA and protein were collected and detected by realtime PCR and western blot, respectively. (A) LPS (10 ng/ml) incubation significantly increased TLR4 mRNA expression which was inhibited by resveratrol in dose-dependent way. (B) Western blot showed the similar changes of TLR4 protein expression. TLR4 expression was induced by LPS but significantly inhibited by resveratrol in dose-dependent way. ${ }^{*} \mathrm{P}<0.05$ vs. control group; ${ }^{\#} \mathrm{P}<0.05$ vs. Lipopolysaccharide (LPS) group $(n=4)$. Res: Resveratrol.

role of resveratrol in PF treatment.

Inflammation response is a complex process and lots of signaling pathways are involved in it. Previous study demonstrated that TLR plays a critical role during inflammation and innate immune response (Zhou et al., 2009). Damage associated molecular pattern molecules (DAMPs) and LPS are both capable to bind to TLR4 and LPS is thought a natural ligand of TLR4. The response of
TLR4 activation induced by LPS is usually transduced via the IL-1 receptor signaling complex, which includes two essential adaptor proteins, myeloid differentiation 88 (MyD88) and tumor necrosis factor receptor-associated factor 6 (TRAF6) as well as the IL-1 receptor-associated kinase (IRAK). There is also MyD88-independent pathway such as TIR domain-containing adaptor inducing IFN- $\beta$ (TRIF) and TRIF-related adaptor molecule (TRAM) mediating the action, but NF-KB is recognized as the downstream common mediator of TLR4 signaling pathway (Apetoh et al., 2007; Lu et al., 2008). NF-kB plays as a master switch transactivating LPS's pro-inflammation action. It stimulates the expression of the proinflammatory cytokines IL-1, -6 , and -8 (Takeuchi et al., 2001). It is demonstrated that TLR4 is generally expressed in various lung epithelial cells and stromal cells such as alveolar epithelial cells, bronchial epithelial cells and vascular endothelial cells. TLR4/NF-KB pathway is involved in airway inflammation and other pulmonary inflammatory disease (Perros et al., 2011). In the present study, we observed elevated expression of TLR4 in lung tissue from PF rats, and in vitro experiment showed that LPS incubation activated TLR4/NF-KB pathway in pulmonary fibroblast. Furthermore, LPS induced proliferation of pulmonary fibroblast was abolished after NF$\mathrm{KB}$ inhibition by NF-KB inhibitor BAY 11-7085. But the proliferation of cells was not back to normal level, implying that we cannot exclude other pathway mediating the function of TLR4 except for NF-KB. In fact, IRF3 and MAPK pathway could also be activated by TLR4, which is involved in inflammation regulation (Patel et al., 2011). All these results indicated an important role of TLR4 signaling pathway during inflammation in PF and suggested the critical role of NF-KB in mediating pulmonary fibroblast proliferation in PF. Utilization of NF-KB inhibitor in vivo and gene knockout animal would be helpful to reveal the exact role of TLR4/NF-KB pathway in PF.

Resveratrol is primarily extracted from grapes and other plants. It is abundant in red wine. Lots' of studies have revealed that resveratrol play a protective role in cardiovascular diseases (Bradamante et al., 2004). Recent study also indicated a role of resveratrol in PF, but the underlying mechanism remains unknown. The effect of resveratrol involves several aspects, including antioxidant effect, cyclooxygenase (COX) inhibition, peroxisome proliferator-activated receptor (PPAR) activation, endothelial nitric oxide synthase (eNOS) induction, silent mating type information regulation 2 homolog 1 (SIRT1) activation, etc (Csiszar, 2011; Lagouge et al., 2006; Li et al., 2010). The expansive effect of resveratrol makes it not to only play a protective role in cardiovascular disease, research during past decades have revealed that resveratrol plays an important role in cancer, diabetes, connective tissue disease, etc (Aggarwal et al., 2004; Szkudelska and Szkudelski, 2010; Elmali et al., 2007). Recently, animal experiments have indicated that resveratrol is able to attenuate and even reverse the established PF, but the underlying mechanism is still 
A

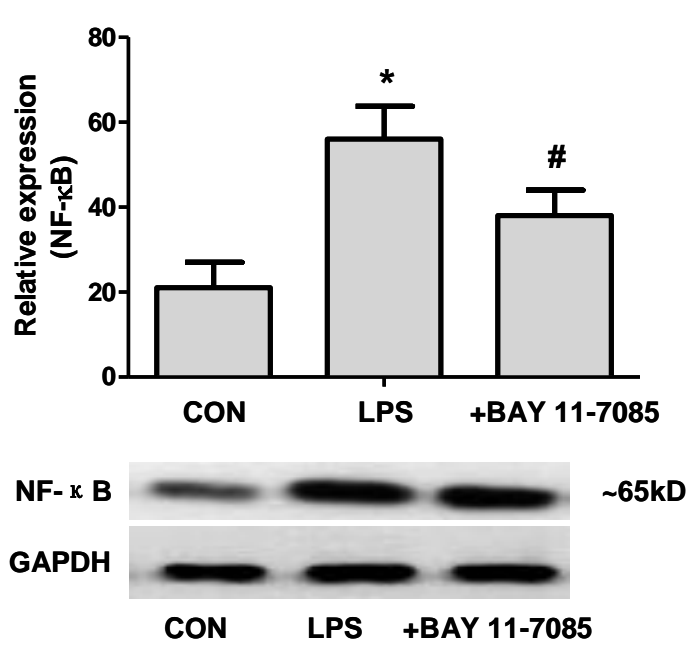

B

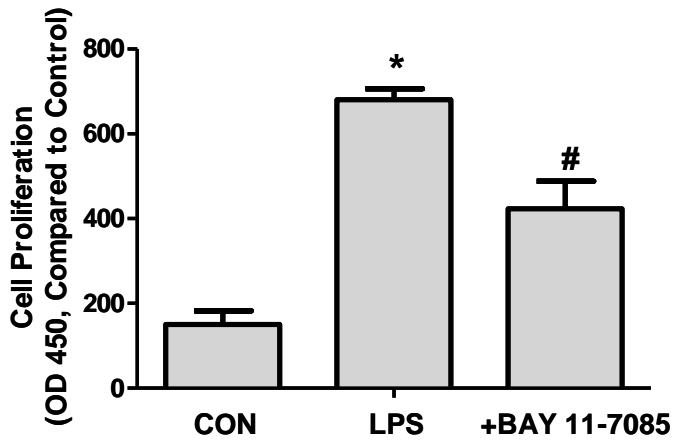

Figure 5. NF-KB inhibiion cancel the effect of LPS and resveratrol on pulmonary fibroblast proliferation. Furthermore, to investigate the role of NF-KB in proliferation regulation by LPS, BAY 11-7085, a NF-KB inhibitor was used. We found that pre-treatment of BAY 11-7085 cancelled the pulmonary fibroblast proliferation induced by LPS, which suggest a critical role of NF-KB in pulmonary fibroblast proliferation regulation. ${ }^{*} \mathrm{P}<0.05$ vs control group; ${ }^{\#} \mathrm{P}<0.05$ vs. Lipopolysaccharide (LPS) group $(n=4)$.

A

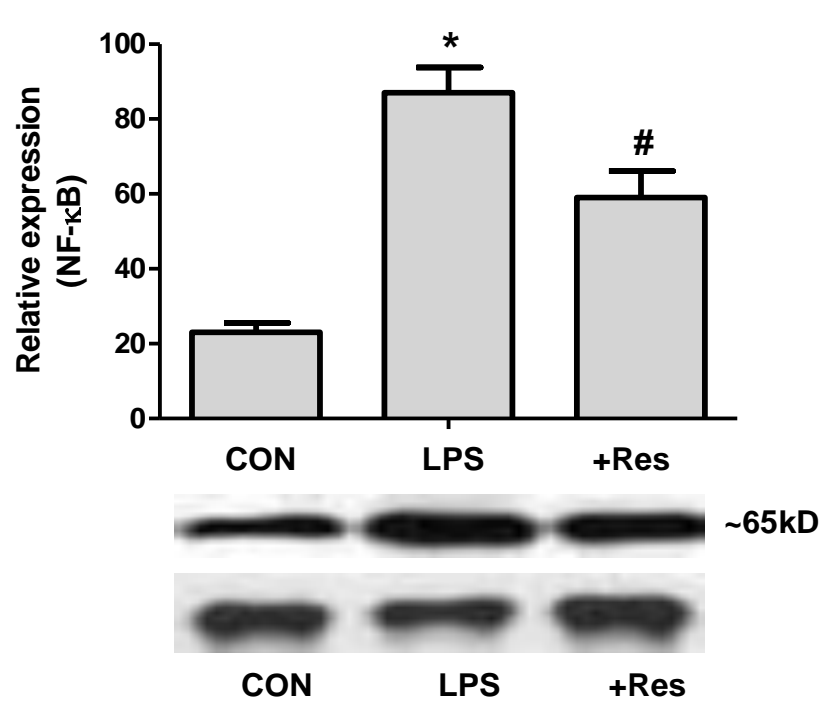

B

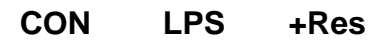

Figure 6. Effect of LPS and resveratrol on NF-KB expression and activity in pulmonary fibroblast. We investigate the direct effect of LPS and resveratrol on NF-KB expression and activity in cells. Pulmonary fibroblasts were cultured with LPS with or without resveratrol for $24 \mathrm{~h}$. Proteins were collected and detected by western blot. Activity of NF-KB was determined by EMSA. (A) LPS (10 ng/ml) incubation significantly increased NF-KB expression which was inhibited by resveratrol. (B) NF-KB was activated by LPS (10 ng/ml) incubation and resveratrol pre-treatment significantly inhibited the activation of NF-KB.

${ }^{*} \mathrm{P}<0.05$ vs. control group; ${ }^{\#} \mathrm{P}<0.05$ vs. Lipopolysaccharide (LPS) group $(n=4)$. Res: Resveratrol.

seldom known (Akgedik et al., 2012).

In the present study, resveratrol treatment downregulated plasma level of inflammatory factors in vivo. Cell culture experiment showed that resveratrol inhibited the activation of TLR4/NF-KB pathway induced by LPS in pulmonary fibroblast. All these results prompted that antiinflammatory effect of resveratrol may contribute its therapeutic role in PF treatment. Sener et al. (2007) found that 
found that in BLM-induced lung injury rats, resveratrol treatment decreased TGF- $\beta$, II-1, II- 6 and TNF- $\alpha$ level. There were also several experiments that suggested the effect of resveratrol on TLR4 signaling pathway. Research from Capiralla et al. (2012) demonstrated that resveratrol mitigated microglial inflammation by inhibiting the TLR4/NF-KB/STAT signaling cascade. But how resveratrol affected TLR4 signaling pathway remains unclear and opposite opinions exist. Someone thought the function was dependent on MyD88 pathway while a few research said it did not. Different mechanism may attribute to different tissue and cell types. Deeper investigation is needed to finally answer the question of how can resveratrol interact with TLR4 signaling pathway in pulmonary fibroblast.

The present study investigated the role of resveratrol in PF treatment. We demonstrated the anti-inflammatory effect of resveratrol and its effect on TLR4 signaling pathway. There is still a long way to go for therapeutical utilization of resveratrol. Anyway, the precious constituent of red wine, has been more and more attractive for new drug development. Several structural modifications have been made for avoiding the weakness of resveratrol including low water-solubility, short half-time in vivo, etc. Further research will push the potential candidates to a light future in cardiovascular disease and other diseases treatment.

\section{REFERENCES}

Aggarwal BB, Bhardwaj A, Aggarwal RS, Seeram NP, Shishodia S, Takada Y (2004). Role of resveratrol in prevention and therapy of cancer: preclinical and clinical studies. Anticancer Res. 24:2783840.

Akgedik R, Akgedik S, Karamanlı H, Uysal S, Bozkurt B, Ozol D, Armutcu F, Yıldırım Z (2012). Effect of resveratrol on treatment of bleomycin-induced pulmonary fibrosis in rats. Inflammation 35:1732-41.

Apetoh L, Ghiringhelli F, Tesniere A, Criollo A, Ortiz C, Lidereau R, Mariette C, Chaput N, Mira JP, Delaloge S, André F, Tursz T, Kroemer G, Zitvogel L (2007). The interaction between HMGB1 and TLR4 dictates the outcome of anticancer chemotherapy and radiotherapy. Immunol Rev. 220:47-59.

Bradamante S, Barenghi L, Villa A (2004). Cardiovascular protective effects of resveratrol. Cardiovasc. Drug Rev. 22:169-88.

Bringardner BD, Baran CP, Eubank TD, Marsh CB (2008). The role of inflammation in the pathogenesis of idiopathic pulmonary fibrosis. Antioxid. Redox Signal. 10:287-301

Capiralla H, Vingtdeux V, Zhao H, Sankowski R, Al-Abed Y, Davies $P$, Marambaud P (2012). Resveratrol mitigates lipopolysaccharide- and $A \beta$-mediated microglial inflammation by inhibiting the TLR4/NF-KB/STAT signaling cascade. J. Neurochem. 120(3):461-472

Csiszar A (2011). Anti-inflammatory effects of resveratrol: possible role in prevention of age-related cardiovascular disease. Ann NY Acad. Sci. 1215:117-122.

Davies HR, Richeldi L (2002). Idiopathic pulmonary fibrosis: current and future treatment options. Am. J. Respir. Med. 1:211-124.
Elmali N, Baysal O, Harma A, Esenkaya I, Mizrak B (2007). Effects of resveratrol in inflammatory arthritis. Inflammation 30:1-6.

Gasse P, Riteau N, Vacher R, Michel ML, Fautrel A, di Padova F, Fick L, Charron S, Lagente V, Eberl G, Le Bert M, Quesniaux VF, Huaux F, Leite-de-Moraes M, Ryffel B, Couillin I (2011). IL-1 and IL-23 mediate early IL-17A production in pulmonary inflammation leading to late fibrosis. PLoS One 6:e23185.

John G, Yildirim AO, Rubin BK, Gruenert DC, Henke MO (2010). TLR-4-mediated innate immunity is reduced in cystic fibrosis airway cells. Am. J. Respir. Cell. Mol. Biol. 42:424-31

Lagouge M, Argmann C, Gerhart-Hines Z, Meziane H, Lerin C, Daussin F, Messadeq N, Milne J, Lambert P, Elliott P, Geny B, Laakso M, Puigserver P, Auwerx J (2006). Resveratrol improves mitochondrial function and protects against metabolic disease by activating SIRT1 and PGC-1alpha. Cell 127:1109-22.

Li W, He X, Shi W, Jia H, Zhong B (2010). Pan-PPAR agonists based on the resveratrol scaffold: biological evaluation and docking studies. Chem. Med. Chem. 5:1977-82

Lu YC, Yeh WC, Ohashi PS (2008). LPS/TLR4 signal transduction pathway. Cytokine 42:145-51.

Noble PW, Barkauskas CE, Jiang D (2012). Pulmonary fibrosis: patterns and perpetrators. J. Clin. Investig. 122:2756-2762.

Oikonomou N, Harokopos V, Zalevsky J, Valavanis C, Kotanidou A, Szymkowski DE, Kollias G, Aidinis V (2006). Soluble TNF mediates the transition from pulmonary inflammation to fibrosis. PLoS One 27:e108.

Patel SJ, Jindal R, King KR, Tilles AW, Yarmush ML (2011) The inflammatory response to double stranded DNA in endothelial cells is mediated by NFKB and TNFa. PLoS One. 6:e19910.

Perros F, Lambrecht BN, Hammad H (2011). TLR4 signalling in pulmonary stromal cells is critical for inflammation and immunity in the airways. Respir. Res. 24:12:125.

Sener G, Topaloğlu N, Sehirli AO, Ercan F, Gedik N (2007). Resveratrol alleviates bleomycin-induced lung injury in rats. Pulm. Pharmacol. Ther. 20(6):642-649.

Serlin DM, Kuang PP, Subramanian M, O'Regan A, Li X, Berman JS, Goldstein RH. (2006) Interleukin-1beta induces osteopontin expression in pulmonary fibroblasts. J. Cell. Biochem. 97:519-29.

Szkudelska K, Szkudelski T (2010). Resveratrol, obesity and diabetes. Eur. J. Pharmacol. 10:635:1-8.

Takeuchi O, Akira S (2001). Toll-like receptors; their physiological role and signal transduction system. Int. Immunopharmacol. 1:625-35.

Taniguchi $H$, Ebina $M$, Kondoh $Y$, Ogura T, Azuma A, Suga $M$, Taguchi Y, Takahashi H, Nakata K, Sato A, Takeuchi M, Raghu G, Kudoh S, Nukiwa T (2010). Pirfenidone Clinical Study Group in Japan (2010). Pirfenidone in idiopathic pulmonary fibrosis. Eur Respir. J. 35:821-829.

Yang HZ, Wang JP, Mi S, Liu HZ, Cui B, Yan HM, Yan J, Li Z, Liu H, Hua F, Lu W, Hu ZW (2012). TLR4 activity is required in the resolution of pulmonary inflammation and fibrosis after acute and chronic lung injury. Am. J. Pathol. 180:275-92.

Zhou H, Andonegui G, Wong CH, Kubes P (2009). Role of endothelial TLR4 for neutrophil recruitment into central nervous system microvessels in systemic inflammation. J. Immunol. 183:5244-5250. 